\title{
SERUM IGFBP-2 LEVELS ARE ASSOCIATED WITH REDUCED INSULIN SENSITIVITY IN OBESE CHILDREN
}

Steven W. Yau ${ }^{1,2}$, Brooke E. Harcourt ${ }^{1,2}$, Kung-Ting Kao ${ }^{1,2}$, Erin J. Alexander ${ }^{1}$, Vincenzo C. Russo $^{1,2}$, George A. Werther ${ }^{1,2}$, Matthew A. Sabin ${ }^{1,2}$

${ }^{1}$ Obesity Research, Murdoch Childrens Research Institute and The Royal Children's Hospital, Parkville, Victoria, 3052, Australia and ${ }^{2}$ Department of Paediatrics, University of Melbourne, Melbourne, Victoria, 3052, Australia.

Address correspondence to: A/Prof Matthew Sabin, Department of Endocrinology and Diabetes, The Royal Children's Hospital, 50 Flemington Road, Parkville, Victoria 3052, Australia. Tel: + 6139345 5951. Fax: + 6139347 7763. E-mail: matt.sabin@rch.org.au

Key Words: IGFBP-2, fat mass, insulin sensitivity, paediatric obesity

Running Head: Serum IGFBP-2 in children with obesity

Total Word Count: 2553

Abstract Word Count: 220

References: 30

Tables and Figures: $2 / 1$

Supplementary Tables and Figures: 1

Abbreviations: IGFBP-2, Insulin-like growth factor binding protein 2 (IGFBP-2); COBRA, Childhood Overweight Biorepository of Australia; RCH, The Royal Childrens Hospital; OGTT, oral glucose tolerance test; ALT, alanine aminotransferase; GGT, gamma-glutamyl trans peptidase; ALP, alkaline phosphatase; FFQ, food frequency questionnaire; SD, standard

This is the author manuscript accepted for publication and has undergone full peer review but has not been through the copyediting, typesetting, pagination and proofreading process, which may lead to differences between this version and the Version of Record. Please cite this article as doi: 10.1111/cob.12245

This article is protected by copyright. All rights reserved. 
deviation.

This article is protected by copyright. All rights reserved. 


\section{1. 'What is already known about this subject?'}

- The GH/IGF-1 axis plays a central role in childhood growth and development.

- IGFBP-2 appears to be associated with insulin sensitivity.

- IGFBP-2 levels are reduced in obesity and Type 2 diabetes.

\section{'What this study adds?'}

- IGFBP-2 levels are negatively correlated with age, obesity and fasting plasma insulin levels in children.

- IGFBP-2 associates positively with insulin sensitivity, and negatively with triglycerides and blood pressure in obese children after correction for weight status.

- IGFBP-2 levels in obese children do not appear to be associated with diet or physical activity levels.

\section{Abstract}

Background: Insulin-like growth factor binding protein 2 (IGFBP-2) may represent a critical link between body composition and insulin sensitivity. We investigated the relationship between circulating IGFBP-2 levels, body composition, insulin sensitivity, energy intake and physical activity in children with obesity.

Methods: Children were recruited via the Weight Management Service at the Royal Children's Hospital, Melbourne, as part of the Childhood Overweight BioRepository of Australia (COBRA). Comprehensive anthropometric, biochemical and environmental data were collected and compared to serum IGFBP-2 levels (measured by ELISA). Multiple regression modelling was used to assess the influence of circulating IGFBP-2 levels on anthropometric and biochemical measures.

Results: 194 children were included in this study (46\% male). Circulating IGFBP-2 negatively correlated with age, anthropometric measures, blood pressure and insulin concentration. Positive associations were observed between insulin sensitivity index (ISI-HOMA) and serum IGFBP-2. In multiple regression modelling, IGFBP-2 significantly contributes to variance in systolic blood pressure $(-19 \%, p<0.05)$, circulating triglycerides $(-16 \%, p<0.05)$ and ISI-HOMA $(18 \%, p<0.05)$. No associations were observed between dietary energy intake or physical activity and IGFBP-2 levels. 
Conclusions: Circulating IGFBP-2 levels in children with obesity correlate inversely with body mass and markers of metabolic dysfunction, and positively with insulin sensitivity. These findings suggest that reduced levels of IGFBP-2 may play an important role in the pathogenesis of obesity complications in early life.

This article is protected by copyright. All rights reserved. 


\section{Introduction}

In Australia, approximately one third of children are overweight or obese and are at high risk of and metabolic complications including cardiovascular disease and cancers in adult life ${ }^{1}$. Similar to insulin, though with less specificity, insulin-like growth factor-1 (IGF-1) has been shown to regulate blood glucose levels through its insulin-like activity on metabolicallyactive cells. The IGF-axis is essential for key biological functions including growth, development and metabolism. The bioavailability of IGFs are modulated by six high affinity IGF-binding proteins (IGFBPs). Insulin has been shown to regulate IGFBP-1, thus modifying IGF-I levels and preventing hypoglycaemia ${ }^{2}$. As a result, IGFBP-1 has been used as a marker of insulin sensitivity ${ }^{2}$. IGFBP-3 has been demonstrated to inhibit adipocyte differentiation ${ }^{3}$ and stimulate beta-cell replication in vitro ${ }^{4}$. Recently, IGFBP-4 was shown to inhibit adipose tissue expansion ${ }^{5}$. IGFBP-5 is important in postnatal growth regulation and affects pancreatic beta-cell growth and metabolism, while IGFBP-6 levels are increased in patients with type 1 diabetes ${ }^{6}$. However, the strongest involvement of IGFBPs in regulating adiposity and glucose metabolism is seen with IGFBP- $2^{7,8}$.

IGFBP-2 is the primary circulating IGFBP in infancy ${ }^{9}$ and is produced by numerous tissues including liver, skeletal muscle and white adipocytes ${ }^{10}$. IGFBP-2 levels are reduced in obese adults and children and these reductions are more prominent in visceral than subcutaneous adipose tissue ${ }^{11}$. Studies in relatively small cohorts of children reported lower circulating IGFBP-2 concentrations in children with obesity ${ }^{12}$ and that circulating levels of IGFBP-2 were positively associated with insulin sensitivity in prepubertal obese children ${ }^{13}$.

The aim of this study was to comprehensively investigate the relationships between circulating IGFBP-2, anthropometric measures, insulin sensitivity, dietary macro and micronutrient intake and physical activity parameters in a large clinical cohort of overweight and obese Australian children. We hypothesised that decreased IGFBP-2 levels would associate with lower levels of insulin sensitivity, and that IGFBP-2 concentrations would further associate with diet and physical activity parameters. 


\section{Materials and Methods}

\section{Study Design}

The study population was recruited via the Weight Management Service at The Royal Children's Hospital (RCH) Melbourne, as part of the 'Childhood Overweight BioRepository of Australia (COBRA)' study. Recruitment and sample collection protocols have been previously described ${ }^{14}$. In brief, data collection included anthropometric, clinical, and environmental measurements, collected at the initial clinical appointment and via self-administered questionnaires completed by the child's primary caregiver. A fasting venipuncture sample was collected for analysis of biochemical parameters including serum analysis of IGFBP-2 for this study. The study protocol was approved by the RCH Human Research Ethics Committee, RCH, Melbourne, Australia (HREC Ref. No: 28081).

\section{Assessment of Pre-diabetes, Diabetes and Insulin Sensitivity}

Fasting insulin and glucose were obtained in children $<10$ years old and an oral glucose tolerance test (OGTT) was performed in children $\geq 10$ years old. Serum glucose was quantified by the Beckman Glucose oxidase method using $\mathrm{O}_{2}$ electrode (Beckman Coulter Pty Ltd, NSW, Australia). Serum insulin was quantified by the Roche Cobas ${ }^{\circledR} 6000$ analyzer (Roche, Switzerland). A specialist paediatric endocrinologist or a consultant general paediatrician assessed the patient's pubertal stage by Tanner staging. The threshold cutpoints utilised for diagnosis of insulin resistance were fasting insulin levels of; $>15 \mathrm{mU} / \mathrm{I}$ 'prepubertal', >30 mU// 'peri-pubertal' and >20 mU/l 'post-pubertal' ${ }^{15}$. 'Pre-diabetes' included both impaired fasting glucose $=5.6 \mathrm{mmol} / \mathrm{L}$ to $<7 \mathrm{mmol} / \mathrm{L}$, and impaired glucose tolerance $=7.8$ $\mathrm{mmol} / \mathrm{L}$ to $<11.1 \mathrm{mmol} / \mathrm{L}$ at 2 hour of $\mathrm{OGTT}^{16}$. Insulin sensitivity index was calculated by homeostasis model assessment (HOMA) [ISI-HOMA= 405/(glucose (milligrams per decilitre) $x$ insulin (microunits per millilitre)). Insulin resistance was calculated by HOMA-IR= (glucose (milligrams per decilitre) $\mathrm{x}$ insulin (microunits per millilitre))/405, and classified according to pubertal status.

Biochemistry, Nutrition and Physical Activity Analysis 
Circulating serum alanine aminotransferase (ALT), gamma-glutamyl transferase (GGT), alkaline phosphatase (ALP), triglyceride, cholesterol levels (total, HDL and LDL), calcium and phosphate levels were measured using standard laboratory methods (Ortho Clinical Diagnostics Vitros ${ }^{\circledR}$ 5600, Johnson and Johnson, New Brunswick, NJ, USA and Beckman Coulter UniCel ${ }^{\circledR}$ DxC 800, Beckman Coulter, Brea, CA USA). Serum IGFBP-2 protein was quantified using an enzyme-linked immunosorbent assay (ELISA) in accordance with the manufacturer's instructions (IGFBP-2 DuoSet ELISA DY674, R\&D Systems, Inc. Minneapolis, MN, USA, intra-assay CV\%; $4.5 \%$ and inter-assay CV\%; 5.5\%).

Nutritional intake was assessed via the self-administered food frequency questionnaire (FFQ, Newcastle Innovation, Newcastle NSW, Australia). Assessment included dietary analysis of proportion of energy derived from; proteins, fats (saturated, monounsaturated and polyunsaturated), carbohydrates, sugars and fibre. Data on micronutrient intake was also collected including vitamins (folate) and minerals (calcium, phosphate and magnesium). Physical activity was assessed by continuous wear of a wrist Actical accelerometer for nine days. This allowed for analysis of; total physical activity, moderate-vigorous physical activity and total sedentary time using accompanying software (Actical, Mini Mitter Co. inc, Bend, OR, USA).

\section{Statistics}

Data sets are presented as mean \pm standard deviation (SD). Each variable was tested for normal distribution and variables that had a skewed distribution were log-transformed before analyses. These included data for, serum IGFBP-2, blood pressure, lipids, glucose, insulin, HOMA-IR, and ISI-HOMA. Associations between IGFBP-2 and other variables were calculated by Pearson's correlation coefficients. Means were compared for continuous data using Student's t-test or one-way ANOVA with Tukey's post-hoc analysis. Associations of IGFBP-2 with metabolic risk factors were investigated by multiple regression analyses adjusted for age, sex and with/without BMI. Statistical analyses were performed using SPSS (SPSS version 20.0; SPSS, Inc., Chicago, IL). Values of $p<0.05$ were considered statistically significant. 


\section{Results}

A total of 194 patients ( $46 \%$ male) were included in this study. As demonstrated by the anthropometric characteristics, this population is characterised as overweight and obese with BMI z-scores ranging from 1.33-4.35 (Table 1). Circulating levels of IGFBP-2 were higher in children with greater insulin sensitivity, and lower in those children with greater body mass, greater waist circumference/ height ratio and higher percentage of total body fat mass and truncal fat mass (Table 1). Additionally, we observed that lower IGFBP-2 concentrations in children are associated with increases in both systolic and diastolic blood pressure (SBP and DBP, Table 1). The mean serum IGFBP-2 concentration in this population was $40.8( \pm 25.7 \mathrm{SD} \mathrm{ng} / \mathrm{ml})$, and ranged from $11.7-176.6 \mathrm{ng} / \mathrm{ml}$. Serum concentrations of IGFBP-2 were higher in male than female study participants $(36.9( \pm 26.5 \mathrm{SD}) \mathrm{pg} / \mathrm{ml} \mathrm{v}$ $36.9( \pm 23.0 \mathrm{SD}) \mathrm{pg} / \mathrm{ml} ; p=0.023)$. Sex specific differences were not observed in other parameters; BMI z-score, total body fat percentage, truncal body fat percentage $(p>0.05)$.

Serum IGFBP-2 concentrations were higher in pre-pubertal compared to peri- and postpubertal subgroups (Figure 1A). Overweight and obese children with insulin resistance had significantly lower serum IGFBP-2 concentrations than their non-insulin resistant peers (Figure 1B). Patients with impaired glucose tolerance also exhibited lower levels of IGFBP-2 than patients with normal glucose tolerance (Figure 1C).

A total of 133 patients completed the food frequency questionnaire. No significant relationships were observed between nutritional macro and micro-nutrient parameters and serum IGFBP-2 concentrations (Supplemental Table 1). A total of $40 \%(n=78)$ of the study population consented to wearing wrist actical accelerometers and had valid results for analysis. Pearson's correlations were performed to assess the relationship between total physical activity time, physical activity levels and total sedentary time with serum IGFBP-2 concentrations. No significant associations were observed between these parameters with serum IGFBP-2 levels (results not shown).

The influence of circulating IGFBP-2 levels on anthropometric and biochemical factors was then considered via multiple regression modelling. Preliminary analysis ensured that no violation of the assumption of normality, linearity, multicolinearity or homoscedasticity had occurred in the models. Each model was determined to be statistically significant via ANOVA 
(Table 2). In the model controlling for age and sex, circulating IGFBP-2 concentrations independently contributed to SBP, DBP, circulating triglyceride concentrations and insulin sensitivity (Table 2). Secondary adjustment of the model to include BMI, age and sex, demonstrated that IGFBP-2 concentrations independently contribute to SBP, circulating triglycerides and insulin sensitivity index (Table 2).

This article is protected by copyright. All rights reserved. 


\section{Discussion}

Decreased circulating IGFBP-2 levels aligned with markers of metabolic dysfunction in our study of a paediatric population with overweight and obesity. Further, our findings support a strong clinical link between IGFBP-2 and insulin sensitivity, as indicated by low circulating IGFBP-2 associating with higher fasting insulin levels and reduced insulin sensitivity. In line with previous reports, we have demonstrated that circulating IGFBP-2 concentrations are significantly reduced in children with increased body mass ${ }^{12,13}$, but expanded this to include peri and post pubertal adolescents. Furthermore, we have demonstrated that IGFBP-2 levels are not associated with diet or physical activity levels in obese children.

Studies in adults have shown that IGFBP-2 is associated with insulin resistance, as reductions in IGFBP-2 are seen at early stages of insulin resistance development ${ }^{17}$. Here we demonstrate that children with insulin resistance or impaired glucose tolerance have significantly lower levels of IGFBP-2. Previous studies have shown that low levels of circulating IGFBP-2 are independently associated with the development of T2DM and the metabolic syndrome ${ }^{18}$. IGFBP-2 concentrations observed in the serum of our population were significantly lower than previous studies in both healthy and overweight adolescents, though these populations were not enriched to analyse obesity complications such as insulin resistance and impaired glucose tolerance ${ }^{19}$. Another possible explanation is that IGFBPs are thought to act synergistically to bind IGFs, therefore levels of these other IGFPBs may be compensatory in our population. IGFBP-1 has previously been shown to strongly associate with insulin resistance in children with obesity ${ }^{20}$. Whilst IGFBP-3 is the major circulating IGFBP and binds up to $75 \%$ of circulating IGFs in large complexes, it acts predominantly in a growth-hormone dependent manner and was not related to insulin resistance HOMA in a cross-sectional or longitudinal analysis of overweight youth ${ }^{20}$. Genetic variations of IGFBP-5 have been linked with metabolic syndrome in studies of adults, but less is known about its potential contribution to metabolic dysfunction in children ${ }^{21}$. We have further demonstrated that serum IGFBP-2 concentrations not only correlate positively with HOMA insulin sensitivity index, and negatively with fasting insulin concentrations and HOMA insulin resistance index, but that IGFBP-2 concentrations independently contribute to insulin sensitivity. 
In accordance with previous findings, in this cohort of overweight and obese children, subjects with reduced circulating IGFBP-2 weighed more and had increased total body fat mass $^{12}$. In vitro studies have shown that IGFBP-2 appears capable of directly inhibiting adipogenesis, whilst in vivo preclinical models show that IGFBP-2 overexpression protects against obesity and diabetes ${ }^{22}$. Recently, our laboratory demonstrated a depot-specific effect of IGFBP-2 inhibiting adipogenesis and lipogenesis in visceral adipocytes, but not subcutaneous adipocytes ${ }^{11}$, suggesting that IGFBP-2 may have an adipose-specific role in the regulation of body composition. Our findings also indicate an inverse relationship between visceral adiposity in children and circulating IGFBP-2, as indicated by the relationship between increased truncal obesity and decreased IGFBP-2 levels. Additional modulation of the IGF-axis has previously been described in adolescent females, whereby weight loss led to increased levels of IGFBP-2 and improved cardiovascular risk factors ${ }^{23}$.

Furthermore, we demonstrate that circulating IGFBP-2 levels decrease with age. This finding is in accordance with previous reports that IGFBP-2 levels declined from infancy to adolescence $^{24}$. Puberty is associated with a reduction in insulin sensitivity, however this is modulated by a 2 -fold increase in insulin production independent to changes in percentage fat mass ${ }^{25}$. Here, we demonstrated that IGFBP-2 levels varied depending on pubertal stage, with levels of IGFBP-2 higher in pre-pubertal than in peri- and post-pubertal obese children. Others have demonstrated that when insulin resistance was classified according to pubertal stages, IGFBP-2 levels were higher in more insulin sensitive subjects than less insulin sensitive subjects ${ }^{15}$. Furthermore, individuals with impaired glucose tolerance had lower levels of IGFBP-2 than those without impaired glucose tolerance. Together, these findings demonstrate that IGFBP-2 negatively correlated with pubertal development, insulin resistance and impaired glucose tolerance.

In accordance with previous findings in rodent models and in human studies, we have demonstrated an association between systolic and diastolic blood pressure and IGFBP-2 levels ${ }^{10,18}$. Circulating IGFBP-2 has previously been highlighted for its potential to serve as a biomarker for cardiovascular disease ${ }^{18}$. We modelled these findings and additionally demonstrated that decreases in IGFBP-2 circulating concentrations independently attribute to both systolic and diastolic blood pressure. Future development of therapeutics carefully 
targeted to the metabolic actions of IGFBP-2, which act to reinstate IGFBP-2 serum concentrations, and not the cellular proliferative actions noted in various carcinomas, in obesity may protect against the onset of hypertension in this susceptible population, as this has previously been demonstrated, albeit in pre-clinical models ${ }^{10}$.

Interestingly, serum IGFBP-2 levels in our cohort did not correlate with our analysis of nutrition intake or physical activity. IGFBP-2 was previously found to have minimal relationship with dietary intake compared to other IGF axis proteins IGFBP-1 and IGFBP-3, which are significantly modulated by changes in macro and micronutrient consumption in a similarly obese population ${ }^{26}$. In a large population study, overall consumption of dairy and calcium was associated with lower concentrations of IGFBP-2, whilst increased dietary monounsaturated fats were associated with increased IGFBP-2 concentrations ${ }^{27}$. Similarly, in a large animal model, our group previously demonstrated the association between monounsaturated fatty acid ingestion, reduction in IGFBP-2, promotion of visceral adiposity and decline in insulin sensitivity ${ }^{28}$.

Whilst we observed associations between IGFBP-2 levels, body composition and insulin sensitivity, these observations were not reflected by changes in physical activity levels in our study. Again this may be a reflection of the cross-sectional design of our study which investigated a disease-only population, as others have previously demonstrated the effect of exercise on modulation of IGFBP-2, though not in obese populations. Increases in circulating IGFBP-2 levels are consistently seen in moderate intensity/long duration ${ }^{29}$ or acute/heavyresistance training ${ }^{30}$, in healthy adolescents ${ }^{31}$, adults ${ }^{32}$ and elderly individuals ${ }^{33}$. The effect of training on circulating levels of IGFBP-2 in children, lean or obese, remains unknown.

Our study has some potential limitations. Its cross-sectional design does not allow for us to establish a causal relationship between IGFBP-2 and anthropometric or metabolic measurement. Analysis of the relationship between IGFBP-2 and physical activity was limited, as only $40 \%$ of the study population consented to wearing an Actical device, and this may have introduced bias through excluding children that were less active.

In summary, our data demonstrate that circulating IGFBP-2 levels in children and adolescents with obesity inversely correlate with obesity and its metabolic markers, while positively correlating with insulin sensitivity. When adjusted for age, sex and BMI, we show 
that circulating IGFBP-2 levels independently influence insulin sensitivity, blood pressure and triglycerides but not fat mass. Furthermore, serum IGFBP-2 levels in our obese paediatric cohort did not correlate with a survey of dietary intake or physical activity, whilst these results require further confirmation in an intervention study, it is possible that circulating IGFBP-2 levels in children with obesity, may be more regulated through hormonal or other intrinsic factors, rather than nutritional changes.

This article is protected by copyright. All rights reserved. 


\section{Conflicts of interest statement}

The authors declare that there is no conflict of interest that could be perceived as prejudicing the impartiality of the research reported.

\section{Acknowledgements}

We are grateful for the contribution of COBRA cohort participants.

Funding for this study was from the Murdoch Childrens Research Institute. Authors from the Murdoch Childrens Research Institute are supported in part by the Victorian Government Operational Infrastructure Support Program. MAS and BEH were supported by the National Health and Medical Research Council, Professional Training Fellowship (MAS: APP1012201) and Peter Doherty Early Career Fellowship (BEH: APP1072086). SWY was supported by an Australian Postgraduate Award scholarship.

Author contributions: SWY analysed IGFBP-2 concentration in serum samples, conducted preliminary analysis of the results and drafted the manuscript. BEH oversaw and conducted analysis of results, drafted and edited the manuscript. KTK collected clinical data and edited the manuscript. EJA recruited patients to the COBRA study and collected clinical data. VCR supervised the analysis of IGFBP-2 and edited the manuscript. GAW supervised the project and edited the manuscript. MAS conceptualised and oversaw the project, collected clinical data and edited the manuscript. All authors approve of the final version of the manuscript.

\section{References}

1 Deshmukh-Taskar P, Nicklas TA, Morales M, Yang SJ, Zakeri I, Berenson GS. Tracking of overweight status from childhood to young adulthood: the Bogalusa Heart Study. Eur J Clin Nutr. 2006; 60: 48-57.

2 Hoeflich A, Russo VC. Physiology and pathophysiology of IGFBP-1 and IGFBP-2 consensus and dissent on metabolic control and malignant potential. Best practice \& research Clinical endocrinology \& metabolism. 2015; 29: 685-700.

3 Chan SSY, Schedlich LJ, Twigg SM, Baxter RC. Inhibition of adipocyte differentiation by insulin-like growth factor-binding protein-3. Am J Physiol Endocrinol Metab. 2009; 296: E654-63.

4 Palau N, Rebuffat SA, Altirriba J, Piquer S, Hanzu FA, Gomis R, et al. Role of IGFBP-3 in the regulation of ${ }^{2}$-cell mass during obesity: adipose tissue $/{ }^{2}$-cell cross talk. Endocrinology. 2012; 153: 177-87. 
5 Gealekman O, Gurav K, Chouinard M, Straubhaar J, Thompson M, Malkani S, et al. Control of adipose tissue expandability in response to high fat diet by the insulin-like growth factor binding protein-4. J Biol Chem. 2014; 289: 18327-38.

6 Lu SS, Purohit S, Sharma A, Zhi WB, He MF, Wang YQ, et al. Serum insulin-like growth factor binding protein 6 (IGFBP6) is increased in patients with type 1 diabetes and its complications. Int J Clin Exp Med. 2012; 5: 229-37.

7 Sabin MA, Yau SW, Russo VC, Clarke IJ, Dunshea FR, Chau J, et al. Dietary monounsaturated fat in early life regulates IGFBP2: implications for fat mass accretion and insulin sensitivity. Obesity (Silver Spring). 2011; 19: 2374-81.

8 Yau SW, Henry BA, Russo VC, McConell GK, Clarke IJ, Werther GA, et al. Leptin enhances insulin sensitivity by direct and sympathetic nervous system regulation of muscle IGFBP-2 expression: evidence from nonrodent models. Endocrinology. 2014; 155: 2133-43.

9 Bhala A, Harris M, Zirin S, Corcoran L, Cohen P. Insulin-like growth factor axis parameters in sick hospitalized neonates. J Pediatr Endocrinol Metab. 1998; 11: 451-59.

10 Wheatcroft S, Kearney M, Shah A, Ezzat V, Miell J, Modo M. IGF-binding protein-2 protects against the development of obesity and insulin resistance. Diabetes. 2007; 56: 28494.

11 Yau SW, Russo VC, Clarke IJ, Dunshea FR, Werther GA, Sabin MA. IGFBP-2 inhibits adipogenesis and lipogenesis in human visceral, but not subcutaneous, adipocytes. Int J Obes. 2014; 39: 770-81.

12 Ballerini MG, Ropelato MG, Domene HM, Pennisi P, Heinrich JJ, Jasper HG. Differential impact of simple childhood obesity on the components of the growth hormoneinsulin-like growth factor (IGF)-IGF binding proteins axis. $J$ Pediatr Endocrinol Metab. 2004; 17: 749-57.

13 Claudio M, Benjamim F, Riccardo B, Massimiliano C, Francesco B, Luciano C. Adipocytes IGFBP-2 expression in prepubertal obese children. Obesity. 2010; 18: 2055-57.

14 Sabin MA, Clemens S, Saffery R, McCallum Z, Campbell M, Kiess W, et al. New directions in childhood obesity research: how a comprehensive biorepository will allow better prediction of outcomes. BMC Med Res Methodol. 2010; 10: 100.

15 Viner RM, White B, Barrett T, Candy DCA, Gibson P, Gregory JW, et al. Assessment of childhood obesity in secondary care: OSCA consensus statement. Arch Dis Childhood-Educ Pract Ed. 2012; 97: 98-105. 
16 American Diabetes Association. Diagnosis and Classification of Diabetes Mellitus. Diabetes Care. 2010; 33: S62-S69.

17 Arafat AM, Weickert MO, Frystyk J, Spranger J, Schofl C, Mohlig M, et al. The role of insulin-like growth factor (IGF) binding protein-2 in the insulin-mediated decrease in IGFI bioactivity. J Clin Endocrinol Metab. 2009; 94: 5093-101.

18 Heald AH, Kaushal K, Siddals KW, Rudenski AS, Anderson SG, Gibson JM. Insulinlike growth factor binding protein-2 (IGFBP-2) is a marker for the metabolic syndrome. Exp Clin Endocrinol Diabetes. 2006; 114: 371,76.

19 Wex H, Vorwerk P, Mohnike K, Bretschneider D, Kluba U, Aumann V, et al. Elevated serum levels of IGFBP-2 found in children suffering from acute leukaemia is accompanied by the occurrence of IGFBP-2 mRNA in the tumour clone. British Journal of Cancer. 1998; 78: 515-20.

20 Reinehr T, Kleber M, Toschke AM, Woelfle J, Roth CL. Longitudinal association between IGFBP-1 levels and parameters of the metabolic syndrome in obese children before and after weight loss. Int J Pediatr Obes. 2011; 6: 236-43.

21 Kallio P, Tolppanen AM, Kolehmainen M, Poutanen K, Lindstrom J, Tuomilehto J, et al. Association of sequence variations in the gene encoding insulin-like growth factor binding protein 5 with adiponectin. Int J Obes (Lond). 2009; 33: 80-8.

22 Hedbacker K, Birsoy K, Wysocki RW, Asilmaz E, Ahima RS, Farooqi IS, et al. Antidiabetic effects of IGFBP2, a leptin-regulated gene. Cell Metab. 2010; 11: 11-22.

23 Wabitsch M, Blum WF, Muche R, Heinze E, Haug C, Mayer H, et al. Insulin-like growth factors and their binding proteins before and after weight loss and their associations with hormonal and metabolic parameters in obese adolescent girls. International Journal of Obesity. 1996; 20: 1073-80.

24 Smith W, Nam T, Underwood L, Busby W, Celnicker A, Clemmons D. Use of insulin-like growth factor-binding protein-2 (IGFBP-2), IGFBP-3, and IGF-I for assessing growth hormone status in short children. The Journal of Clinical Endocrinology \& Metabolism. 1993; 77: 1294-99.

25 Hannon TS, Janosky J, Arslanian SA. Longitudinal study of physiologic insulin resistance and metabolic changes of puberty. Pediatr Res. 2006; 60: 759-63.

26 Brand-Miller JC, Liu V, Petocz P, Baxter RC. The glycemic index of foods influences postprandial insulin-like growth factor-binding protein responses in lean young subjects. Am J Clin Nutr. 2005; 82: 350-4. 
27 Crowe FL, Key TJ, Allen NE, Appleby PN, Roddam A, Overvad K, et al. The association between diet and serum concentrations of IGF-I, IGFBP-1, IGFBP-2, and IGFBP3 in the european prospective investigation into cancer and nutrition. Cancer Epidemiol Biomarkers Prev. 2009; 18: 1333-40.

28 Sabin MA, Russo VC, Azar WJ, Yau SW, Kiess W, Werther GA. IGFBP-2 at the interface of growth and metabolism- implications for childhood obesity. Pediatr Endocrinol Rev. 2011; 8: 382-93.

29 Rarick KR, Pikosky MA, Grediagin A, Smith TJ, Glickman EL, Alemany JA, et al. Energy flux, more so than energy balance, protein intake, or fitness level, influences insulinlike growth factor-I system responses during 7 days of increased physical activity. Journal of Applied Physiology. 2007; 103: 1613-21.

30 Nindl BC, Kraemer WJ, Marx JO, Arciero PJ, Dohi K, Kellogg MD, et al. Overnight responses of the circulating IGF-I system after acute, heavy-resistance exercise. $J$ Appl Physiol. 2001; 90: 1319-26.

31 Eliakim A, Brasel JA, Mohan S, Wong WLT, Cooper DM. Increased physical activity and the growth hormone IGF-I axis in adolescent males. Am J Physiol-Regul Integr Comp Physiol. 1998; 275: R308-R14.

32 Berg U, Enqvist JK, Mattsson CM, Carlsson-Skwirut C, Sundberg CJ, Ekblom B, et $a l$. Lack of sex differences in the IGF-IGFBP response to ultra endurance exercise. Scand $J$ Med Sci Sports. 2008; 18: 706-14.

33 Deuschle M, Blum WF, Frystyk J, Orskov H, Schweiger U, Weber B, et al. Endurance training and its effect upon the activity of the GH-IGFs system in the elderly. Int $J$ Sports Med. 1998; 19: 250-54.

\section{Figure Legends}

Figure 1: (A) Pubertal stage; 'pre-pubertal' $(n=78)$, 'peri-pubertal' $(n=42)$, 'post-pubertal' ( $n=51),(B)$ insulin resistance; No ( $n=99)$, Yes ( $n=81)$ and (C) Impaired Glucose Tolerance; No $(n=56)$, Yes $(n=40)$. Serum IGFBP-2 and fasting insulin were log-transformed for analysis. 


\section{Tables}

Table 1. Anthropometric and biochemical characteristics and correlations between serum IGFBP-2 levels and anthropometric/biochemical measurements.

\begin{tabular}{|lcccc|}
\hline & $\begin{array}{c}\text { Number } \\
\text { of } \\
\text { patients* }\end{array}$ & Mean( \pm SD) & r & p value \\
\hline Sex & 194 & & & \\
Age (male/female) & $90 / 104$ & & & \\
Height (cm) & 194 & $11.0( \pm 3.6)$ & -0.206 & $\mathbf{0 . 0 0 4}$ \\
Weight (kg) & 194 & $150.2( \pm 19.3)$ & -0.216 & $\mathbf{0 . 0 0 2}$ \\
BMI (kg/m ${ }^{2}$ ) & 194 & $75.5( \pm 31.6)$ & -0.202 & $\mathbf{0 . 0 0 5}$ \\
BMI z-score & 194 & $31.8( \pm 7.1)$ & -0.203 & $\mathbf{0 . 0 0 4}$ \\
Waist circ. (cm) & 194 & $2.4( \pm 0.4)$ & -0.055 & 0.450 \\
SBP (mmHG) & 179 & $96.2( \pm 26.9)$ & -0.069 & 0.371 \\
DBP (mmHG) & 179 & $113.1( \pm 15.9)$ & -0.201 & $\mathbf{0 . 0 0 7}$ \\
\% Total fat mass & 179 & $66.3( \pm 8.9)$ & -0.171 & $\mathbf{0 . 0 2 2}$ \\
\% Truncal fat mass & 168 & $40.2( \pm 11.8)$ & -0.171 & $\mathbf{0 . 0 2 7}$ \\
Triglyceride & 185 & $34.7( \pm 11.7)$ & -0.166 & $\mathbf{0 . 0 3 6}$ \\
Cholesterol & 189 & $4.2( \pm 0.5)$ & -0.241 & $\mathbf{0 . 0 0 3}$ \\
HDL & 112 & $1.3( \pm 0.7)$ & -0.100 & 0.173 \\
LDL & 112 & $2.7( \pm 0.6)$ & -0.149 & 0.119 \\
ALT & 189 & $37.3( \pm 25.7)$ & 0.046 & 0.529 \\
GGT & 189 & $22.3( \pm 13.9)$ & -0.061 & 0.404 \\
ALP & 189 & $212.0( \pm 83.3)$ & -0.021 & 0.779 \\
Fasting glucose & 190 & $4.6( \pm 0.5)$ & -0.046 & 0.553 \\
Fasting insulin & 181 & $22.5( \pm 17.3)$ & -0.197 & $\mathbf{0 . 0 0 8}$ \\
HOMA-IR & $4.5( \pm 3.9)$ & -0.165 & $\mathbf{0 . 0 2 2}$ \\
ISI (HOMA) & & $8.0( \pm 17.8)$ & 0.229 & $\mathbf{0 . 0 0 2}$ \\
\hline
\end{tabular}

* Not all measurements were available for each study participant. 
Abbreviations: ALT, alanine aminotransferase; ALP, alkaline phosphatase; BMI, body mass index; BMI z-score; age sex adjusted BMI (CDC); GGT, gamma-glutamyl transferase; HDL, High density lipoprotein cholesterol; HOMA, homeostasis model of assessment; IGFBP-2, insulin-like growth factor binding protein-2; IR, insulin resistance; ISI, Insulin sensitivity Index; LDL, Low density lipoprotein cholesterol; r, Pearson's correlation coefficient. Bold values statistically significant, $p<0.05$

Table 2. Multiple regression analysis for the independent influence of IGFBP-2 on metabolic risk factors after adjusting for i) age and sex, ii) age, sex and BMI.

\begin{tabular}{|c|c|c|c|c|c|c|}
\hline & \multicolumn{2}{|c|}{ i) Age, Sex } & \multirow{2}{*}{$\begin{array}{c}\text { Model ANOVA } \\
\mathbf{F} \text { (df: Regression, } \\
\text { Residual) } \boldsymbol{p} \text { value }\end{array}$} & \multicolumn{2}{|c|}{ ii) Age, Sex, BMI } & \multirow{2}{*}{$\begin{array}{c}\text { Model ANOVA } \\
\text { F (df: Regression, } \\
\text { Residual) } p \text { value }\end{array}$} \\
\hline & $\beta$ & $\mathbf{p}$ & & $\beta$ & $\mathbf{p}$ & \\
\hline Waist Circ. & 0.009 & 0.837 & $3.15(3,166) 0.027$ & 0.085 & 0.413 & $2.88(4,165) 0.024$ \\
\hline SBP & -0.225 & 0.011 & $6.59(3,175)<0.001$ & -0.194 & 0.032 & $5.30(4,174)<0.001$ \\
\hline DBP & -0.163 & 0.044 & $5.72(3,175) 0.001$ & -0.149 & 0.069 & $4.61(4,174) 0.001$ \\
\hline$\%$ Total fat mass & -0.129 & 0.133 & $4.15(3,163) 0.007$ & -0.099 & 0.326 & $3.187(4,162) 0.015$ \\
\hline$\%$ Truncal fat mass & -0.118 & 0.203 & $3.97(3,156) 0.009$ & -0.135 & 0.088 & $3.05(4,155) 0.019$ \\
\hline Triglycerides & -0.170 & 0.020 & $5.99(3,181) 0.001$ & -0.162 & 0.028 & $4.74(4,180) 0.001$ \\
\hline Glucose & -0.026 & 0.722 & $4.82(3,186) 0.003$ & -0.030 & 0.642 & $3.99(4,185) 0.004$ \\
\hline Insulin & -0.093 & 0.311 & $4.33(3,177) 0.006$ & -0.113 & 0.210 & $3.66(4,176) 0.007$ \\
\hline HOMA IR & -0.086 & 0.291 & $4.36(3,176) 0.006$ & 0.048 & 0.408 & $4.11(4,188) 0.003$ \\
\hline ISI (HOMA) & 0.182 & 0.014 & $6.52(3,176)<0.001$ & 0.180 & 0.015 & $5.27(4,175)<0.001$ \\
\hline
\end{tabular}

Abbreviations: IGFBP-2, insulin-like growth factor binding protein-2; Waist circ., waist circumference; SBP, systolic blood pressure; DBP, diastolic blood pressure; HOMA, homeostasis model of assessment; IR, insulin resistance; ISI, Insulin sensitivity Index; 
Supplementary Table 1. Correlations between serum IGFBP-2 levels and dietary energy intake.

\begin{tabular}{|lccc|}
\hline & $\begin{array}{c}\text { Number of } \\
\text { patients }\end{array}$ & $\mathbf{r}$ & $\boldsymbol{p}$ value \\
\hline Energy & 133 & 0.016 & 0.854 \\
Protein & 133 & 0.001 & 0.992 \\
Fats & 133 & 0.038 & 0.663 \\
Saturated Fats & 133 & 0.084 & 0.335 \\
Monounsaturated Fats & 133 & 0.011 & 0.896 \\
Polyunsaturated Fats & 133 & -0.054 & 0.540 \\
Cholesterol & 133 & -0.021 & 0.809 \\
Carbohydrate & 133 & 0.011 & 0.896 \\
Sugars & 133 & 0.021 & 0.811 \\
Water & 133 & 0.017 & 0.842 \\
Fibre & 133 & -0.078 & 0.370 \\
Thiamine & 133 & -0.016 & 0.857 \\
Riboflavin & 133 & 0.011 & 0.896 \\
Niacin & 133 & -0.026 & 0.764 \\
Folate & 133 & -0.078 & 0.370 \\
Vitamin A & 133 & -0.094 & 0.280 \\
Vitamin C & 133 & -0.077 & 0.380 \\
Retinol & 133 & -0.033 & 0.709 \\
Beta Carotene & 133 & -0.124 & 0.155 \\
Sodium & 133 & -0.002 & 0.978 \\
Potassium & 133 & -0.014 & 0.871 \\
Magnesium & 133 & -0.010 & 0.908 \\
Calcium & 133 & 0.077 & 0.378 \\
Phosphorus & 133 & 0.025 & 0.772 \\
Iron & 133 & -0.098 & 0.260 \\
Zinc & 133 & -0.055 & 0.530 \\
\hline
\end{tabular}

Abbreviations: IGFBP-2, insulin-like growth factor binding protein-2; r, Pearson's correlation coefficient. 
12. Figures

Figure 1

A

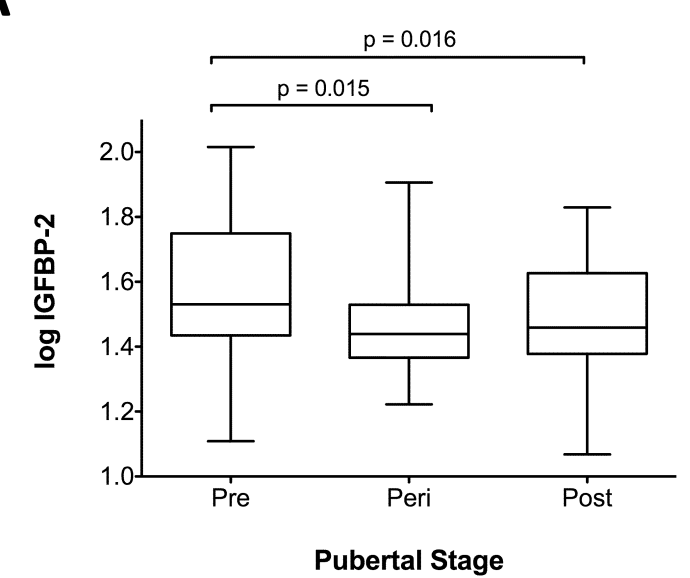

B

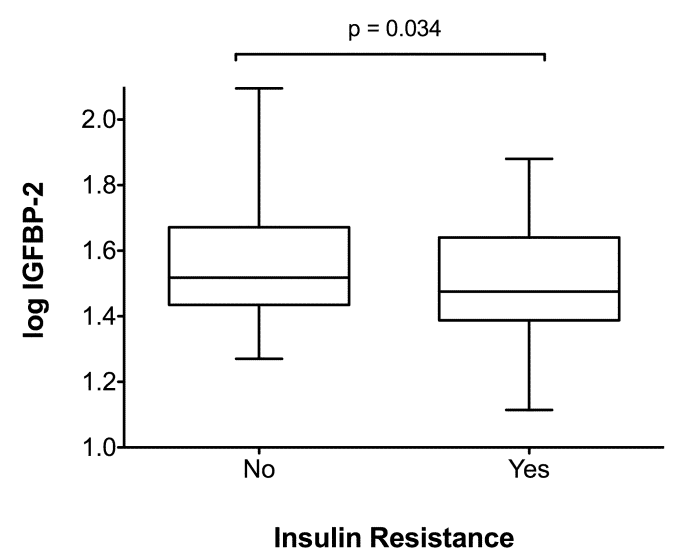

C

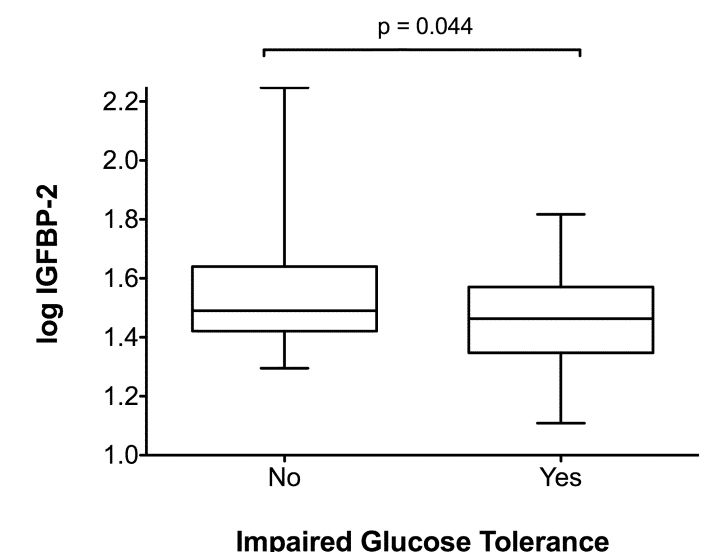




\section{Please wait...}

If this message is not eventually replaced by the proper contents of the document, your PDF viewer may not be able to display this type of document.

You can upgrade to the latest version of Adobe Reader for Windows®, Mac, or Linux® by visiting http://www.adobe.com/go/reader_download.

For more assistance with Adobe Reader visit http://www.adobe.com/go/acrreader.

Windows is either a registered trademark or a trademark of Microsoft Corporation in the United States and/or other countries. Mac is a trademark
of Apple Inc., registered in the United States and other countries. Linux is the registered trademark of Linus Torvalds in the U.S. and other countries. 


\section{Please wait...}

If this message is not eventually replaced by the proper contents of the document, your PDF viewer may not be able to display this type of document.

You can upgrade to the latest version of Adobe Reader for Windows®, Mac, or Linux® by visiting http://www.adobe.com/go/reader_download.

For more assistance with Adobe Reader visit http://www.adobe.com/go/acrreader.

Windows is either a registered trademark or a trademark of Microsoft Corporation in the United States and/or other countries. Mac is a trademark
of Apple Inc., registered in the United States and other countries. Linux is the registered trademark of Linus Torvalds in the U.S. and other countries. 
A

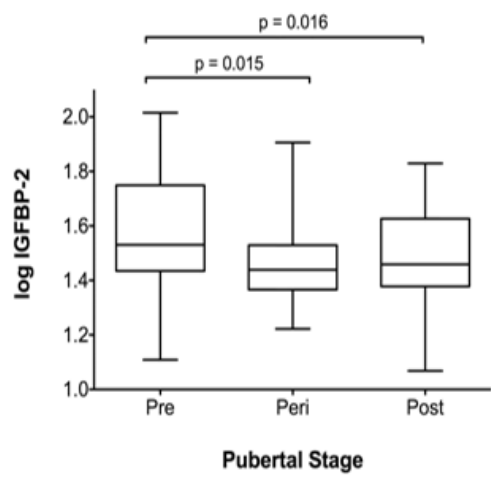

B

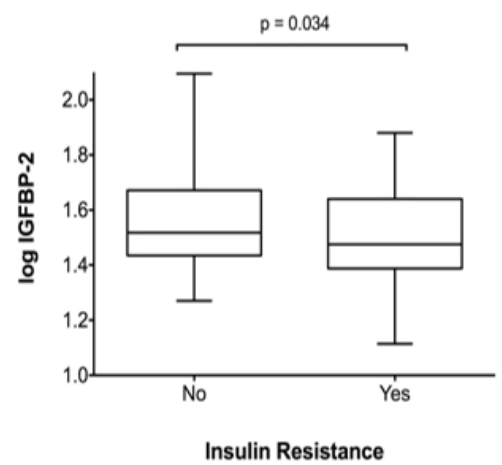

C

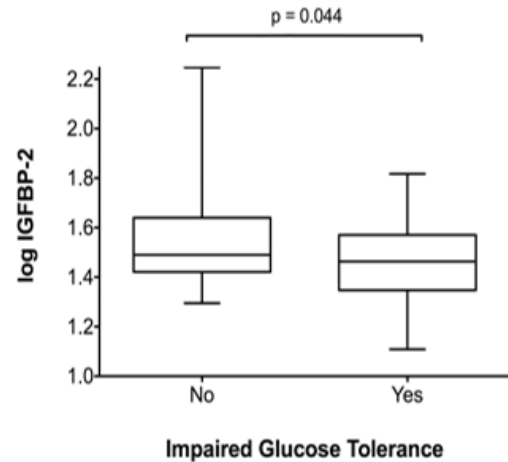

Figure1.tif

This article is protected by copyright. All rights reserved. 


\section{Please wait...}

If this message is not eventually replaced by the proper contents of the document, your PDF viewer may not be able to display this type of document.

You can upgrade to the latest version of Adobe Reader for Windows®, Mac, or Linux® by visiting http://www.adobe.com/go/reader_download.

For more assistance with Adobe Reader visit http://www.adobe.com/go/acrreader.

Windows is either a registered trademark or a trademark of Microsoft Corporation in the United States and/or other countries. Mac is a trademark
of Apple Inc., registered in the United States and other countries. Linux is the registered trademark of Linus Torvalds in the U.S. and other countries. 


\section{Please wait...}

If this message is not eventually replaced by the proper contents of the document, your PDF viewer may not be able to display this type of document.

You can upgrade to the latest version of Adobe Reader for Windows®, Mac, or Linux® by visiting http://www.adobe.com/go/reader_download.

For more assistance with Adobe Reader visit http://www.adobe.com/go/acrreader.

Windows is either a registered trademark or a trademark of Microsoft Corporation in the United States and/or other countries. Mac is a trademark
of Apple Inc., registered in the United States and other countries. Linux is the registered trademark of Linus Torvalds in the U.S. and other countries. 


\section{Please wait...}

If this message is not eventually replaced by the proper contents of the document, your PDF viewer may not be able to display this type of document.

You can upgrade to the latest version of Adobe Reader for Windows®, Mac, or Linux® by visiting http://www.adobe.com/go/reader_download.

For more assistance with Adobe Reader visit http://www.adobe.com/go/acrreader.

Windows is either a registered trademark or a trademark of Microsoft Corporation in the United States and/or other countries. Mac is a trademark
of Apple Inc., registered in the United States and other countries. Linux is the registered trademark of Linus Torvalds in the U.S. and other countries. 


\section{Please wait...}

If this message is not eventually replaced by the proper contents of the document, your PDF viewer may not be able to display this type of document.

You can upgrade to the latest version of Adobe Reader for Windows®, Mac, or Linux® by visiting http://www.adobe.com/go/reader_download.

For more assistance with Adobe Reader visit http://www.adobe.com/go/acrreader.

Windows is either a registered trademark or a trademark of Microsoft Corporation in the United States and/or other countries. Mac is a trademark
of Apple Inc., registered in the United States and other countries. Linux is the registered trademark of Linus Torvalds in the U.S. and other countries. 


\section{Please wait...}

If this message is not eventually replaced by the proper contents of the document, your PDF viewer may not be able to display this type of document.

You can upgrade to the latest version of Adobe Reader for Windows®, Mac, or Linux® by visiting http://www.adobe.com/go/reader_download.

For more assistance with Adobe Reader visit http://www.adobe.com/go/acrreader.

Windows is either a registered trademark or a trademark of Microsoft Corporation in the United States and/or other countries. Mac is a trademark
of Apple Inc., registered in the United States and other countries. Linux is the registered trademark of Linus Torvalds in the U.S. and other countries. 


\section{University Library}

\section{- M M N E R VA A gateway to Melbourne's research publications}

Minerva Access is the Institutional Repository of The University of Melbourne

Author/s:

Yau, SW;Harcourt, BE;Kao, K-T;Alexander, EJ;Russo, VC;Werther, GA;Sabin, MA

Title:

Serum IGFBP-2 levels are associated with reduced insulin sensitivity in obese children

Date:

2018-06-01

Citation:

Yau, S. W., Harcourt, B. E., Kao, K. -T., Alexander, E. J., Russo, V. C., Werther, G. A. \& Sabin, M. A. (2018). Serum IGFBP-2 levels are associated with reduced insulin sensitivity in obese children. CLINICAL OBESITY, 8 (3), pp.184-190. https://doi.org/10.1111/cob.12245.

Persistent Link:

http://hdl.handle.net/11343/283690 